\title{
Pembelajaran Kooperatif Model Jigsaw Untuk Meningkatkan Ketrampilan Proses Dan hasil Belajar Mempersiapkan Pendirian Usaha Siswa Kelas XII Penjualan A SMK Negeri Pasirian.
}

\author{
Sri Hartatik ${ }^{\mathbf{1}}$
}

\author{
${ }^{1}$ Business and Management Education, SMK Negeri Tempursari \\ Email: hartatik68@gmail.com
}

\begin{abstract}
:
Pemilihan metode pembelajaran sangat menentukan kualitas pengajaran dalam proses belajar mengajar, untuk mencapai tujuan pembelajaran diperlukanpenggunaan metode pembelajaran yang optimal. Hal ini berarti untuk mencapai pengajaran yang berkualitas, setiap pengajaran hams diorganisasikan dandisampaikan pada siswa den gan metode pembelajaran yang tepat.
\end{abstract}

Salah satu model pembelajaran menurut peneliti yang dapat meningkatkan ketrampilan proses dan hasil belajar siswa adalah pendekatan pembelajarankooperatif model jigsaw. Kelebihan pembelajaran kooperatif model jigsaw adalah cara yang efisien dalam mcnarik pehatian siswa mempelajari suatu materi pelajaran.

Proses belajar jigsaw mendorong untuk mendengarkan, inegklasifikasi, mendiskiipsikan iubungan antar beberapa variable, membuat prediksi, menyepakaii,mengkomunikasikan, dan bertanggung jawab dengan memberi setiap anggota dari kelompok bagia yang penting dibahas dalam aktivitas akademik.

Hal ini sesuai dengan penelitian Sakdiyah (2002) yang menyatakan bahwa siswa yang diajar dengan metode pembelajaran kooperatif model jigsaw memilikiprestasi lebih tinggi dari pada siswa yang diajar dengan menggunakan metode pembelajaran konvensional.Terbukti bahwa Proses Pembelajaran dengan Pendekatan jigsaw mampu meningkatkan aktifitas siswa sehingga mereka termotivasi untuk terus belajar demi mencapai prestasi..

Kata Kunci : Pembelajaran Kooperatif Model Jigsaw, mempersiapkan Pendirian Usaha, ketrampilan proses, dan hasil belajar kognitif.

\section{Background}

Mengajar pada dasamya adalah menata lingkungan agar siswa dapat melakukan kegiatan belajar dengan sebaik-baiknya. Pemilihan metode pembelajaran sangat menentukan kualitas pengajaran dalam proses belajar mengajar dan untuk mencapai tujuan pembelajaran diperlukan penggunaan metode pembelajaran yang optimal. Hal ini berarti untuk mencapai pembelajaran yang berkualitas, setiap pembelajaran harus diorganisis dan disampaikan pada siswa dengan metode pembelajaran yang tepat.

Dalam pembeiajaran Kewirausahaan para guru biasanya menggunakan pengajaran dengan pendekatan faktual, materi pelajaran yang disajikan berupa teori dan cerita wirausahawan yang sukses, siswa hanya menerima informasi yang disampaikan oleh guru sehingga kurang memberikan kebebasan kepada siswa untuk berekpresi. Dengan pendekatan faktual siswa memperoleh fakta- fakta dalam teori dan cerita saja, bukannya tidak mungkin pada diri siswa timbul kesan bahwa menjadi seorang wirausahawan yang sukses itu bisa dengan hanya mempelajari teori dan mendengarkan cerita dari guru saja. Barangkali penyajian bahan pelajaran Kewirusahaan yang hanya berupa fakta-fakta dengan metode ceramah itulah yang tidak memberikan ketrampilan proses dan membangkitkan minat siswa sehingga hasil belajarnya rendah. Menurut pengalaman peneliti penyajian materi Kewirausahaan dengan pendekatan faktual menggunakan metode ceramah (pembelajaran konvensional) merupakan pembelajaran yang kurang bermakna dan ketuntasan hasil belajar belum pemah mencapai $70 \%$.

Suatu kelas dikatakan tuntas belajar apabila lebih dari atau sama dengan $80 \%$ siswa telah memiliki daya serap minimal $70 \%$. Dari 
analisis ketuntasan hasil belajar siswa inilah pembelajaran perlu diberdayakan dalam rangka untuk meningkatkan ketrampilan proses dan hasil belajar siswa.

Pemililian metode pembelajaran sangat menentukan kualitas pengajaran dalam proses belajar mengajar, untuk mencapai tujuan pembelajaran diperlukan menggunakan yang optimal. Hal ini berarti untuk mencapai pengajaran berkualitas setiap pengajaran harus diorganisir dan disampaikan pada siswa dengan metode pembelajaran yang tepat.

Salah satu pendeketen model pembelajaran menururt peneliti yang dapat meningkatkan ketrampilan proses hasil belajar siswa adalah pendekatan peinbelajaran kooperatif model Jigsaw. Kelebihan dari pembelajaran koopertif model jigsaw adalah cara yang efisien dalam menarik perhatian siswa dalam mempelajari suatu materi pelajaran. Proses belajar jigsaw mendorong untuk mendengarkan,, mengklasifikasi, medeskripsikan hubungan antara beberapa variabel, membuat prediksi, menyepakati, mengkomunikasikan, dan bertanggung jawab dengan memberi setiap anggota dari kelompok bagian yang penting dibahas dalam aktifitas akademik. Setiap kelompok harus bekerja bersama sebagai tim untuk mencapai tujuan bersama. Pembelajaran kooperatif model jigsaw juga baik untuk meningkatkan aktifitas pembelajaran. Pembelajaran kooperatif model jigsaw mampu me;ningkatkan dan memotifikasi siswa untuk aktif dan mengikuti pelajaran. Hal ini sesuai dengan penelitian Sakdiyah (2002) yang menyatakan bahwa siswa yang diajar dengan metode pembelajaran kooperatif model jigsaw memiliki prestasi lebih tinggi dari pada siswa yang diajar dengan menggunakan pembelajaran konvensional. Berdasarkan latar belakang tersebut di atas maka penelitian dengan judul "Pembelajaran Kooperatif Model Jigsaw Untuk meningkatkan Ketrampilan Proses Dan Hasil Belajar Persiapan Pendirian Usaha Siswa Kelas XII Penjualan A SMK Negeri Pasirian"perlu dilakukan. I

\section{KAJIAN PUSTAKA}

\section{Pembelajaran Kooperatif}

Dalam pembelajaran kooperatif (Cooperative Leaming) memerlukan pendekatan pengajaran melalui penggunaan kelompok kecil siswa untuk bekerjasama dalam memaksimalkan kondisi belajar dalam mencapai tujuan belajar (Holubec, 2001). Pembelajaran kooperatif adalah kegiatan belajar mengajar secara kelompokkelompok kecil, siswa belajar dan bekerjasama untuk sampai pada pengalaman belajar yang optimal, baik pengalaman individual maupun kelompok (Santoso,
1996:6). Menurut Nurhadin, dkk (2004:61) Pembelajaran kooperatif adalah pembelajaran yang secara sadar dan sengaja mengembangkan interaksi yang silih asuh ( saling tenggang rasa) untuk "menghindari ketersinggungan dan kesalahpahaman yang dapat menimbulkan permusuhan.

Johnson dan Johnson (1991)(dalam Syakdiyah,2002:7) menyatakan dalam pembelajaran kooperatif siswa bekerjasama untuk belajar dan bertanggung jawab terhadap keberhasilan belajar dirinya sendiri dan juga keberhasilan belajar kelompoknya.

Dari beberapa definisi tersebut, dapat disimpulkan bahwa pembelajaran kooperatif merupakan metode pembelajaran yang didasarkan atas kerja kelompok yang dilakukan untuk mencapai tujuan khusus. Selain itu juga untuk memecahkan soal dalam memahami suatu konsep yang didasari rasa tanggungjawab dan berpandangan bahwa semua siswa selain mempelajari materi juga harus mempelajari ketrampilan kooperatif. Ketrampilan kooperatif berfungsi untuk melancarkan peranan hubungan kerja dan peranan tugas agar kelompok dapat bekerjasama secara produktif. Agar kondisi tersebut dapat tercapai maka guru harus memahami unsur dasar dari belajar kooperatif.

Menunit Rahayu (1998:157) unsur dasar yang harus ada dalam belajar kooperatif yaitu :

a. Saling ketergantungan positif (Positive Interdependence)

b. Interaksi langsung ( face to face interaction)

c. Pertanggungjawaban individu (Individual accountability)

d. Ketrampilan berinteraksi antar individu dan kelompok

e. Keaktifan proses kelompok (Group processing)

Peranan guru selama belajar kooperatif

dijelaskan oleh Vonde Kley (dalam Rahayu, 1998:163) adalah selama siswa bekerja dalam kelompok guru bertindak sebagai fasilitator yaitu :

a. Membantu siswa menyelesaikan tugas khusus, mengarahkan siswa, rnemberikan umpan balik yang positif terhadap usahia-usaha siswa dalam menyelesaikan tugas.

b. Membantu siswa bekerja secara kooperatif, untuk itu guru harus memacu siswa untuk memusatkan tugas belajar, saling memberi semangat satu sama lain, merefleksi dalam mengecek pertanyaan dalam anggota kelompok.

\section{Kooperatif Model Jigsaw}

Pembelajaran model Jigsaw merupakan model pembelajaran dari teori belajar soal jigsaw berarti potongan. Rahayu (1998:165) menyatakan, pada dasarnya model jigsaw ini guru membagi satuan informasi yang besar menjadi komponenkomponen lebih kecil. Elliot Aronson (1992) dalam Susanto ( 1999:48) menyatakan jigsaw adalah strategi pembelajaran yang dirancang agar siswa mempelajari kerja kelompok. 
Dalam pembelajaran model ini satuan informasi yang besar dibagi menjadi komponen yang lebih kecil. Para siswa dibagi dalam kelompok kooperatif yang terdiri dari empat orang siswa sehingga setiap anggota bertanggungiawab pada sub topik yang sama membentuk kelompok lagi yang terdiri dari dua atau tiga orang. Siswa ini bekerjasama menyelesaikan tugas kooperatifnya dalam : (a) belajar menjadi ahli dalam sub topik bagiannya, dan (b) merencanakan bagaimana mengajarkan sub topik bagiannya kelompok asal.

Kelebihan dari pembelajaran kooperatif model jigsaw adalah cara yang efisien dalam menarik perhatian siswa mempelajari suatu materi pelajaran.

Proses belajar jigsaw mendorong untuk mendengarkan, menyepakati dan bertanggungiawab dengan memberi setiap anggota dan kelompok bagian yang panting dibahas dalam aktivitas akademik. Setiap kelompok harus bekerja bersama sebagai tim untuk mencapai tujuan bersama.

Ketrampilan Proses

Ketrampilan proses adalah ketrampilan fisik dan mental terkait dengan kemampuankemampuan yang mendasar yang dimiliki, dikuasai, dan aplikasikan dalam suatu kegiatan pembelajaran. Ketrampilan proses dapat dikelompokkan menjadi dua bagian, yaitu ketrampilan proses dasar dan ketrampilan proses terpadu. Dalam ketrampilan proses dasar sesuai dengan namanya tercakup beberapa jenis ketrampilan dasar yang merupakan landasan untuk memperoleh ketrampilan proses terpadu. Untuk memiliki ketrampilan proses dasar dalam pengajaran Kewirausahaan siswa perlu dilatih dalam kegiatan:
a. melakukan observasi
b. melakukan tindakan
c. menafsirkan hasil observasi
d. mengkomunikasikan hasil observasi
e. mengklasifikasi
f. membuat prediksi

Pada ketrampilan proses terpadu, tercakup kegiatan-kegiatan yang bempa :
a. mengidentifikasi usaha
b. membuat proposal usaha
c. membuat surat ijin usaha
d. mendiskripsikan hubungan antara beberapa variabel

e. mengumpulkan data dan mengolah data

f. merumuskan hipotesis

g. merancang pendirian usaha

h. melakukan kcgiatan usaha

Bagi pengajar "kewirausahaan yang sangat penting adalah mengetahui bagaimana cara melatihkan ketrampilan tersebut kepada siswa dalam praktek pengajaran kewirausahaan. Dalam uraian berikut ini peneliti menyajikan beberapa pedoman pelaksanaan, khususnya untuk ketrampilan proses dasar adalah sebagai berikut :

1. Melakukan Observasi
Dengan latihan melakukan observasi siswa dilatih untuk dapat lebih mengenal lingkungannya melalui panca indranya. Infomasi dari basil observasi tersebut dapat mendorong siswa untuk mengetahui lebih lanjut, bertanya, berfikir dan membuat interpretasi. Kemampuan melakukan observasi ini adalah ketrampilan yang paling mendasar dalam pembelajaran kewirausahaan dan penting untuk pengembangan ketrampilan proses yang lain. Tahaptahap yang perlu dilalui dalam melakukan observasi adalah:

a. Melakukan observasi dengan menggunakan lebih dari satu alat indra, misalnya siswa diminta untuk mengamati usaha kecil yang ada di sekitar lingkungannya.

b. Mengamati kcgiatan yang dilakukan oleh perusahaan dalam rangka membuka usaha kecil.

c. Apabila tahap-tahap 1) dan 2) diatas merupakan observasi kualitatif, maka perlu dilakukan observasi kuantitatif. Untuk melatihkan observasi kuantitatif ini di mulailah dengan menggunakan alat ukur yang sederhana dan kemudian meningkat kearah yang lebih rumit. Hasil pengukuran yang diperoleh dapat dipakai untuk menilai kecermatan siswa.

Mengkomunikasikan hasil observasi. Kemampun berkomunikasi dengan pihak lain adalah dasar bagi segala sesuatu yang kita kerjakan. Dalam pembelajaran kewirausahaan cara-cara komunikasi yang sering digunakan adalah dengan memakai cara menjelaskan pada siswa baik secara lisan maupun secara tertulis. Latihan pendahuluan dalam mengkomunikasikan hasil observasi ini misalnya dalam bentuk deskripsi tentang apa yang telah diobservasi. Komunikasi yang efektif haruslah memenuhi persyaratan: jelas, tepat dan tidak menimbulkan keraguan.

\section{Membuat Prediksi.}

Prediksi adalah suatu ramalan tentang observasi apa yang akan terjadi.Kegiatan yang perlu dilatihkan untuk memperoleh kemampuan membuat prediksi adalah :

a). Menunjukkan apakah suatu pemyataan itu merupakan pemyataan observasi, inferensi ataukah prediksi. Untuk keperluan ini siswa terlebih dahulu diberi pedoman bahwa yang dimaksud dengan :

Observasi adalah infomasi yang diperoleh melalui indra. Inferensi adalah penjelasan atau penafsiran terhadap suatu observasi Prediksi adalah ramalan tentang observasi yang akan terjadi.

b). Menyusun suatu prediksi atas dasar pola-pola yang diamati. Sebagai contoh siswa diberi contoh cara pengajuan surat ijin tempat usaha (SITU).

Selanjutnya siswa diminta untuk membuat permohonan SITU. Tugas dapat dikembangkan lebih jauh lagi bagaimana cara membuat surat pernyataan tetangga.

4. Kesimpulan

Dengan menggunakan pendekatan proses dalam pengajaran kewirausahaan yang pada hakekatnya melatih siswa untuk memperoleh ketrampilan- 
ketrampilan proses sehingga dapat dicapai tujuan sbb:

1) Siswa dapat menggunakan metode ilmiah cara berfikir siswa.

2) Membantu siswa dalam mempelajari fakta-fakta yang terjadi dalam dunia usaha.

3) Menciptakan suasana siswa aktif belajar dalam pengajaran kewirausahaan.

\section{HASIL BELAJAR}

Untuk mendapatkan hasil yang baik dalam pembelajaran, kami yakin sepenuhnya bahwa sang guru sangat menentukan kesuksesan hasil belajar siswa. Dr. Georgi Lozanov, seorang peneliti dari Bulgaria yang juga penemu ilmu suggestology, metode yang dikenal sccara kolektif sebagai pembelajaran dipercepat menunjukkan bahwa pengarug Guru sangatlah jelas terhadap kcsuksesan murid ( Lovanov, 1978 ).

Dr. Michal Gazzaniga setuju, "Dorongan Biologis itu alamiah sederhana. Kemampuan atau ketrampilan baru akan berkembang jika diberikan lingkungan model yang sesuai” (Gazzaniga, 1992) Sang guru adalah faktor penting dalam lingkungan belajar dan lingkungan siswa. Jadi peran sang guru lebih dari sekedar pemberi ilmu pengetahuan, Guru adalah rekan belajar, model, pembimbing, fasilitator yang tidak salah lagi sebagai pengubah kesuksesan siswa.

Penelitian juga menunjukkan bahwa lingkungan sosial atau suasana kelas adalah penentu psikologis utama yang mempengaruhi belaja akademis ( Walberg dan Greenberg, 1997 ) Kami mempunyai keyakinan dan sangat percaya bahwa dalam memulai petualangan pembelajaran, tingkat komitmen dan dedikasi sangat diperlukan untuk pembelajaran masa kini dan dalam rangka untuk membentuk komunitas pembelajaran supaya mendukung belajar yang optimal perlu menata konteks panggung belajar yang ideal yaitu:

1. Suasana kelas

Suasana kelas mencakup bahasa yang dipilih, cara menjalin rasa simpati dengan siswa dan sikap terhadap sekolah dan belajar. Suasana yang penuh kegembiraan dalam belajar

2. Landasan

Landasan adalah kerangka kerja, tujuan, keyakinan, kesepakatan, kebijakan, prosedur dan aturan bersama yang memberikan pedoman dalam bekerja dalam komunitas belajar.

Lingkungan adalah cara menata kelas, pencahayaan, warna, pengaturan meja dan kursi, tanaman, musik dan semua hal yang mendukung proses belajar.

4 Rancangan

Rancangan adalah penciptaan terarah unsur-unsur penting yang bisa menumbuhkan minat siswa, mendalami makna dan memahami proses tukar menukar informasi.

Jika keempat aspek ini ditata secara cermat, suatu keajaiban akan terjadi.Konteks itu sendiri benar-benar menciptakan rasa saling memiliki, yang kemudian akan meningkatkan rasa memiliki dan penghargaan, kelas akan menjadi komunitas belajar, tepat yang dituju para siswa dengan senang hati,bukan karena keterpaksaan.

Belajar mempunyai arti suatu akfivitas mental/psikis yang berlangsung dalam interaksi aktif dengan lingkungan yang menghasilkan perubahanperubahan dalam pengetahuan, pemahaman, pemahaman, ketrampilan dan nilai sikap. Dalam penelitian ini, hasil belajajar ditinjau dari perkembangan kognitif, meliputi peningkatan pengetahuan dan pemahaman yang iebih menekankan pada aspek kognitif 6 arah, yaitu: pengetahuan, pemahaman, aplikasi, analisis, sintesis dan evaluasi.

\section{METODE PENELITIAN}

Penelitian ini tergolong "Penelitian Tindakan Kelas " dua siklus, yang bertujuan untuk meningkatkan ketrampilan proses dan hasil belajar Persiapan Pendirian Usaha kelas III Penjualan A SMK Negeri Pasirian. Penelitian ini juga bertujuan untuk mengetahui respon siswa terhadap pembelajaran kooperatif model jigsaw. Pendekatan yang digunakan adalah kualitatif-kuantitatif. Tahaptahap penelitian ini terdiri atas (1) Perencanaan, (2) pelaksanaan tindakan, (3)Observasi dan (4) refleksi

Sebagai subyek penelitian ini adalah siswa kelas XII Penjualan A SMKNegeri Pasirian sejumlah 35 siswa, terdiri atas 10 siswa laki-laki dan 25 siswa perempuan.Waktu penelitian ini dimulai bulan januari sampai dengan Maret 2009 Prosedur Penelitian tindakan kelas ini terdiri dari dua siklus. Masing-masing siklusterdiri atas 4 tahap meliputi : (1) merencanakan, (2) pelaksanaan tindakan, (3)observasi, dan (4) refleksi. 


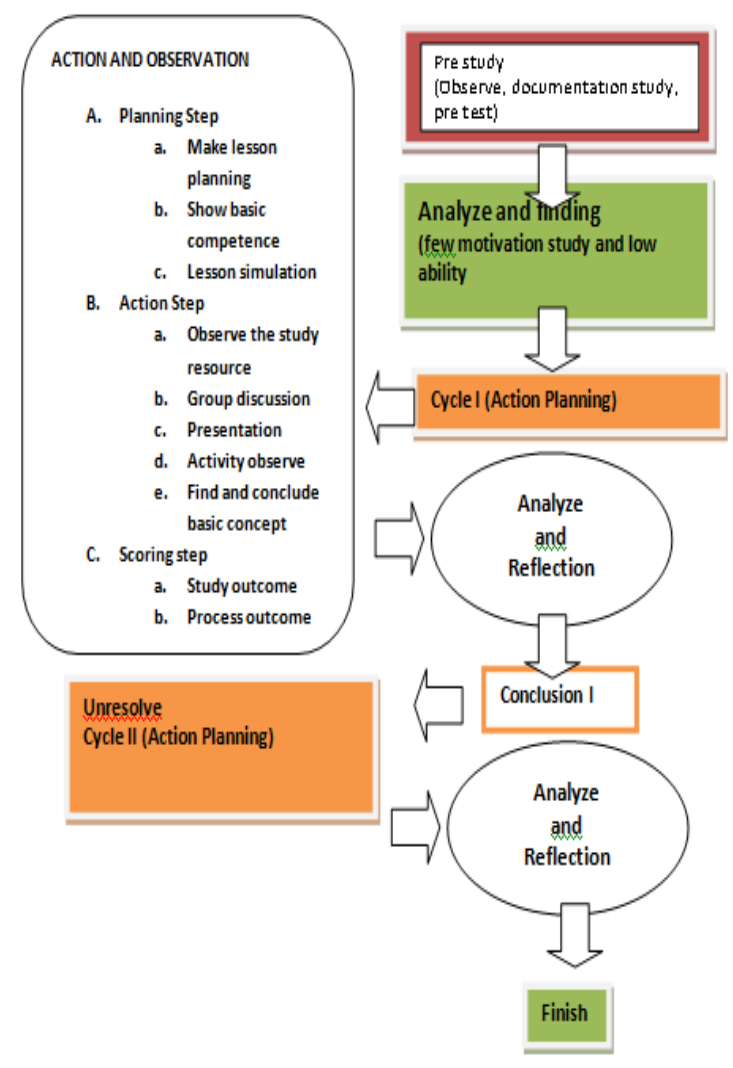

1. Siklus I ( 3 pertemuan $6 \times 45$ menit)

Pokok bahasan mempersiapkan pendirian usaha: petunjuk teknispengurusan ijin usaha, surat ijin tempat usaha, surat ijin usaha perdagangan.

\section{a. Perencanaan}

Tahap perencanaan meliputi kegiatan-kegiatan sebagai berikut ;

1. Menyusun rencana pelaksanaan pembelajaran (RPP) siklus I (Lampiran la)

2. Menyiapkan instrumen, yaitu :

a. Performance Assessment pembelajaran jigsaw (Lampiran 2a)

b. Performance Assessment ketrampilan proses (Lampiran 2b)

c. Post Test hasil belajar (Lampiran 2c)

d. Angket respon siswa (Lampiran 2d)

3. Media Pembelajaran

4. Menyiapkan sumber belajar

\section{b. Pelaksanaan Tindakan}

\section{Pertemuan I ( 2 x 45 menit)}

a. Apresiasi ( 5 menit) : guru membelikan motivasi terkait dengan mempersiapkan pendirian usaha.

b. Membagi kelas menjadi 6 kelompok, setiap kelompok terdiri dari $6-7$ siswa.Pembagian kelompok ahli pada siklus satu (Lampiran 3)

c. Menetapkan siswa dalam kelompok kooperatif (10 menit) :pengelompokan siswa dari kelompok asal kedalam kelompok ahli.

d. Menyiapkan siswa belajar kooperatif ( $6 \mathrm{U}$ menit ), siswa mengerjakanmateri yang diberikan oleh guru dengan kelompok ahli masing-masing, diskusi kelompok asal dilakukan pada pertemuan berikutnya.

\section{Pertemuan II ( 2 x 45 menit)}

a. Siswa kembali ke kelompok asal (5 menit).

b. Siswa menjelaskan materi yang didiskusikan pada kelompok ahli sesuai dengan materi masing-masing pada kelompok asal secara bergiliran (30 menit).

c. Presentasi kelas (petunjuk teknis pengumsan ijin usaha, surat ijin tempat usaha, surat ijin usaha perdagangan).

d. Guru menunjuk tiga, lgfagmpok asal secara acak untukmempresentasikan hasil diskusinya, sedangkan kelompok lainsebagai penyanggah (45 menit).

e. Guru melakukan observasi (pengamatan) selama presentasi kelasberlangsung. V

f. Gum memberikan penguatan atas jawaban yang diberikan siswa (10 menit).

\section{Pertemuan III ( 2 x 45 menit)}

a. Gum memberikan angket sebanyak 11 penanyaan tentang responsiswa terhadap pembelajaran kooperatif model jigsaw (20 menit).

b. Gur memberikan post test tentang petunjuk teknis pengurusan ijinusaha, surat ijin tempat usaha, surat ijin usaha perdagangan (60menit).

c. Guru memberikan hasil pekeijaan siswa dan merekam hasilnyadalam dafiar nilai.

d. Guru memberikan penilaian secara individu maupun kelompok.

\section{c. Observasi}

Pengamatan dilakukan bersamaan dengan pelaksanaan tindakanterhadap selumh aspek nélaksanaan pembelajaran kooperatif model jigsaw, ketrampilan proses, hasil belajar, dan respons siswa.

\section{d. Refleksi}

Pada tahap refleksi dilakukan analisis data untuk mengetahui apakah penelitian tindakan kelas sudah berhasil atau belum. Untuk mengetahui keberhasilan penelitian ditentukan indikator eberhasilanpenelitian sebagai berikut Indikator keberhasilan ketrampilan proses. Penelitian tindakan kelas ini dikatakan berhasil dalammeningkatkan ketrampilan proses apabila rata-rata presentase siswayang melakukan seluruh diskriptor minimal mencapai $85 \%$.

\section{Results and Discussion}

\section{Results}

Hasil Penelitian Penelitian Tindakan Kelas ini meliputi tiga siklus yang masing-masing siklus dilaksanakan dalam tiga kali pertemuan, dengan alokasi waktu 2 x 45 menit untuk setiap pertemuan. Proses Pembelajaran terfokus pada pencapaian Kompetensi Dasar : Kemampuan menganalisis tempat usaha dan penempatan sumber daya manusia. Siklus satu sebagai penjajagan apakah Proses 
Pembelajaran melalui Pendekatan jigsaw dapat berjalan sesuai harapan.

Penerapan Pembelajaran Kooperafif Model

Jigsaw Siklus SatuPelaksanaan tindakan pada siklus I dilakukan tiga kali pertemuan.

Pertemuan Pertama

Ketika guru masuk kelas, sebagai apresiasi gum memberikan dua penanyaan.Pertanyaan pertama yaitu : "Dapatkah kalian menyebutkan contoh surat ijin yangharus dimiliki oleh perusahaan ?’. Ketika itu ada beberapa siswa yangmengacungkan tangannya mau menjawab, yaitu Dwi Fitria, Jayanti, Eka Meilan,dan Evika Mega Putfl untuk menjawab, jawabannya adalah SITU, SIUP, dan IMB.

Pertanyaan kcdua adalah "Apakah yang membedakan ketiga ijin usaha ierscbut ?".Ketika itu banyak yang allgkat_tangan kemudian menunjuk asalah satu siswa yaituKamilah. Kemuadian ydia menjawab, yang' membedakan adalah kalau SITU ijintempat usaha, SI UP ijin usahanya, sedangkan IMB ijin bangunannya.

Kegiatan berikutnya adalah guru membagi kelompok menjadi 6 kelompok,setiap kelompok terdiri dari 5-6 siswa yang $1.1<$-ztrogen berdasarkan jenis kelamin,kemudian dibagi dalam 6 kelompok ahli terdiri atas 5-6 siswa. Pembagiankelompok bexjalan dengan lancar dalam waktu 5 menit siswa sudah menempatitempat duduk dalam kelompoknya masing-masing.

Gum membagi materi dalam kelompok asal yaitu tcknik pengurusan ijin usaha, surat ijin tempat usaha, surat ijin usaha perdagangan, cara emperoleh l-credit, cara bank untuk memperkecil esiko,lembaga keuangan bukan bank. Masing-masing anggota kelompok mendapatkanmateri yang berbeda, kemudian menetapkan siswa dalam kelompok kooperatif (pengelompokan siswa dari kelompokdali kelompok asal kedalam kelompok ahli),siswa mendiskusikan lnateln! yang yang diberikan oleh guru dengan anggotakelompok ahli masing-masing dengan, penuh kesungguhan dan semangat.

Diskusi be-rjalan dengan lancar setiap kelompok dalam suasana yang enjoy dan menyenangkan dan tampak berbeda dengan kegiatan diskusi yang pernah dilakukan sebelumnya_ Diskusi kelompok asal dilakukan pada pertemuan berikutnya.

Pada pertemuan kedua, tahap eksplanasi siswa kenbali ke kelompokasalnya dan mereka bertugas_ menjelaskan materi yang mereka dapat dalam kelompok ahli masing-masing secara bergiliran. Pada tahap ini setiap setiap anggota kelompok saling berinteraksi, masing-masing anggota kelompok menjelaskan konsep secara rinci dan tepat sampai semua anggota kelompok mengerfl yang

dibahas secara keseluruhan, selain itu juga muncul tanya jawab antar anggota kelompok. Benkutnya guru menunjuk tiga kelompok asal secara acak untuk mempresentasikan hasil diskusinya, setiap kelompok yanh presentasi dibagi menjadi dua sesi, yang masing-masing dibatasi tiga penanya sedangkan kelompok lain sebagai penyangga. Pada saat presenlasi penyaji menyampaikan matcri yang cukup jelas dan terorganisir, sering terjadi humor positif, terkadang benanya kenada audien dalam memben kesempatan pada audien untuk berfikir. Pada umumnya para penyaji pada siklus I ini ketika presentasi volume suara kurangj keras, kurang berani menatap audien, sering membelakangi audien, dan ada sebagian kecil audien kurang sungguh-sungguh dalam mengikuti diskusi dalam presentasi. Guru melakukan observasi pada waktu diskusi dan presentasi kelas berlangsung.

Pada pertemuan kefiga tahap evaluasi, yang erupakan akhir dari pelaksanaan siklus, gum memben'kan angket sebanyak 11 pertanyaan tentang responsiswa terhadap pembelajaran kooperatif model jigsaw dan memben'kan post testsecara secara individu tentang mempersiapkan pendirian usaha. Soal terlampir dalam lampiran 2c, selama pelaksanaan tindakan, dilakukan obsewasi dengan cara memberikan angket respon siswa terhadap pembelajaran kooperatif modei jigsaw.

\begin{tabular}{|c|c|c|c|}
\hline \multirow{2}{*}{ No } & \multirow{2}{*}{ Jumlah siswa } & \multicolumn{2}{|c|}{ Rata-ratapersentase ketrampilan proses } \\
\hline & & Siklus I & Siklus II \\
\hline 1 & 37 & $80,1 \%$ & $88,1 \%$ \\
\hline
\end{tabular}

Dari tael 4.1 tersebut diatas dapat dijelaskan bahwa rata-rata persentase ketrampilan proses teijadi peningkatan dari siklus I ke siklus II yang berarti pembelajaran kooperatif model jigsaw dapat meningkatkan kctrampiian proses.

Secara Iebih detail pembelajaran kooperatif model jigsaw dapat meningkatkan ketrampilan proses sebagai berikut;

1). Siswa mengikuti kegiatan pcmbclaj aran dengan gembira

2). Siswa inengikuti kegiatan diskusi secara aktif

3). Siswa mengajukan pertanyaan yang merupakan hasil observasi

4). Siswa berani menjawab pertanyaan yang diajukan guru atau teman

5). Siswa mendengarkan penjelasan yang disampaikan teman dalam kelompoknya

6). Siswa tidak bercakap-cakap suatu hal yang tidak ada hubungannya pelajaran dengan

7). Siswa mengajukan pertanyaan yang merupakan penafsiran / prediksi dari observasi

8). Siswa memberikan respon yang baik dari penanyaan audien

9). Siswa menghargai saran dan pendapat sesama teman peserta diskusi

I0). Siswa saling meniberikan masukan /' kesimpulan dari hasil diskusi 
Hasil penelitian tersebut diatas didukung jugaoleh rata rata data analisis hasil postest siswa.

Tabel 4.2 Nilai rata-rata Post tes dan ketuntasan belajar pada siklus I dan siklus 2

\begin{tabular}{|l|c|c|c|c|c|c|}
\hline \multirow{2}{*}{ Pembelajaran } & Nilai rata- & \multicolumn{2}{|c|}{$\begin{array}{c}\text { Ketuntasan } \\
\text { Individu }\end{array}$} & \multicolumn{3}{|c|}{ Ketuntasan K'lasikal } \\
\cline { 3 - 7 } & rata post tes & Sudah & Belum & $\%$ & Sudah & Belum \\
\hline Siklus I & 78,7 & 31 & 4 & $88,5 \%$ & $\mathrm{~V}$ & \\
Siklus II & 88,5 & 35 & - & $100 \%$ & $\mathrm{v}$ & \\
\hline
\end{tabular}

Tabel 4.3 Respon Siswa Terhadap Pembelajaran Kooperatif Model Jigsaw

\begin{tabular}{|c|c|c|c|}
\hline \multirow{2}{*}{ No } & \multirow{2}{*}{ Jumlah Siswa } & \multicolumn{2}{|c|}{$\begin{array}{c}\text { Rata-rata persentase respon siswa terhadap } \\
\text { Pembelajaran kooperatif model jigsaw }\end{array}$} \\
\cline { 3 - 4 } & & Siklus 1 & Siklus 2 \\
\hline I & 35 & $84,0 \%$ & $85,8 \%$ \\
\hline
\end{tabular}

Dari tabel 4.3 tersebut diatas dapat dijelaskan baliwa rata-rata respon siswaterhadap pembelajaran kooperatif model jigsaw pada siklus I sebesar $84,0 \%$ dansiklus II sebesar 85,8 \%yang berarti terjadj peningkatan respon siswa dari siklus I kesiklus 1l. Dengan kata lain dapat disimpulkan bahwa model pembelajaran kooperatif model jigsaw dapat meningkatkan respon siswa terhadap pembelajaian kooperatif model jigsaw. Secara rinci respon siswa terliadap pembelajaran kopoperatif model jigsaw dapat dijelaskan sebagai berikut:

1. Merasa banyak yang belum diketahui dalam pelajaran Kewirausahaan

2. Kewirausaliaan bennanfaat dalam kehidupan sehari hari

3. Merasa puas jika liasil belajarnya bagus

4. Lebih suka metode diskusi darapada ceramah,

5. Model jigsaw sesuai dengan keinginan siswa

6. Lebih senangjika dibefi pertanyaan guru

7. Model jigsaw meningkatkan keberanian berpendapat

\section{Conclusion}

Dari tiap hasil persiklus pada penelitian tindakan kelas tersebut didapatkan bahwa :
1. Metode pembelaj aran kooperatif model jigsaw dapat meningkatkanketrampilan proses siswa kelas XII Penjualan A SMK Negeri Pasirian pokokbaliasan persiapan pendirian usaha.

2. Raia-raia persentase ketrampilan siswa pada siklus $180,1 \%$ dan siklus II 88,1

3. Metode pembelajaran kooperatif model jigsaw dapat meningkatkan hasil

belajar siswa kelas Xll Penjualan A SMK Negeri Pasirian pokok bahasan persiapan pendirian usaha. '

4. Rata-rafzi nilai hasil belajar siswa pada siklus I adalah 78,7 dan siklus II adalali 88,5.

5. Metode pembelajaran kooperatif model jigsaw dapat menjngkatkan respon siswa kelas XII Penjualan A SMK Negeri Pasirian pokok bahasan persiapan pendirian usaha.

1. 6. Rata-rata persentase respon siswa terhadap pembelajamn kooperatif model

2. jigsaw pada siklus 1 adalah $84,0 \%$ dan siklus II adalah $85,8 \%$.

\section{Suggestion}

Para guru kewirausahaan hendaknya menerapkan pengajaran kooperatif model jigsaw sebagai salah satu pembelajaran yang dapat meningkatkan ketrampilan proses dan hasil belajar siswa.Perlu penelitian tindakan kelas lanj ulan untuk meningkatkan ketrampilan proses dan hasil belajar siswa sehingga pada pengelolaan pembelajaran lebih lanjut dapat menentukan model pembelajaran tepat.

\section{References}

Halutlams, Sakdiyah. 2002. [;fekt1fita.s' pembelajaran Kooperali/'Model Jigsaw Terhadap Preslasi belajar siswa kelas I SM U Negeri 3 Pamekasan. Skripsi tidak diterbitkan. Malang UM.

Husen, A. 2004. Pembelqjaran Kontekstual. Jakarta: Gramedia.

Kamus Besar Bahas Indonesia. 1990. Jakarta: Gramedia.

Khulung, M. 2004. Penerapan model Pembelajaran K00perat[fM0del Jigsaw Unruk Meningkatkan Motivasi dan Prestasi belajar Szlswa Skripsi tidak diterbitkan. Malang UM.

Lie, A 1998. Cooperative Learning. Surabaya: Proyek Perluasan dan Pening,ka_tan Mutu SLTP, 
Kanwil Departemen Pendidikan dan Kebudayaan JawaTimur. LOAN 4042-INO.

Lie, Anita. 2002. Cooperative Lear/ring. Jakarta: Grasindo.

Nurhadi, Yasin Burhan, dan senduk Agus. 2004. Pembelajar-an kontekmal dan Penerapannnya dalam KBK. Malang: UM.

Pusat Pengembangan Kurikulum. 2002. KBK. Jakalta:Depdiknas.

Qodriyah, 2001. Cooperative Learning. Bandung: Angkasa.

Rahayu, S. 1998. Pembelajaran K00peratifDalam Pendidikan IPA. Chimere: Jumal Biologi dan Pengajarannya FPMIPA No. 2 Vol 27 Juli. P 152169.

Santoso. 1996. Cooperative Learning. Jakarta: Media Pustaka.

Trianto, 2007. Model-Model Pembelajaran ln0vatifBer0rien!asi Kontrukrivistik.Jakarta: Prestasi pustaka.

Aldrich, H. \& Reuf, M. 2006. Organizations evolving. London: Sage.

Altinay, L. 2008. The relationship between an entrepreneur's culture and the entrepreneurial behaviour of the firm. Journal of Small Business and Enterprise Development, 15 (1), 111 - 129, (http://dx.doi.org/10.1108/14626000810850874).

Amyx, D., Bhuian, S. \& Shows, G. 2015. Customersalespeople relationship Influence of salespeople entrepreneurial behaviours. Marketing Intelligence \& Planning, $34 \quad$ (5), 586-604, (https://doi.org/10.1108/MIP-09-2015-0170).

Basu, A. \& Goswami, A. 1999. South Asian entrepreneurship in Great Britain: factors influencing growth. International Journal of Entrepreneurial Behaviour \& Research, 5 (5), 251-75.

Battilana, J., Leca B. \& Boxenbaum, E. 2009. How Actors Change Institu- tions: Towards a Theory of Institu- tional Entrepreneurship. Academy of Management Annals, 3, 65-107.

Blackburn, R., Hart, M. \& Wainwright, T. 2013. Small business performance: business, strategy and owner-manager characteristics. Journal of Small Business and Enterprise Development, 20 (1), 8-27, (https://doi.org/10.1108/14626001311298394).
Blesa A. \& Ripolles, M. 2003. The Role Of Market Orientation in the Relationship Between Entrepreneurial Proactiveness and Performance. The Journal of Entrepreneurship, 12, 1.

Bulgerman, L. 2018. A Process Model of Internal Corporate Venturing in the Diversified Major Firm. Administrative Science Quarterly, 28 (2), 223-244

Bunderson, J. \& Thompson, J. 2009. The call of the wild: Zookeepers, callings, and the double-edged sword of deeply meaningful work. Administrative Science Quarterly, 54, 32-57.

Burgelman, R. 1983. A process model of internal corporate venturing in the diversified major firm. Administrative Science Quarterly, 28 (2), 223-44.

Byrnes, J., Miller, D. \& Schafer, W. 1999. Gender differencesinrisk-taking:ameta-analysis.

Psychological Bulletin, 125 ( 3), 367-383.

Camisón, C. 1997. La competitividad de la PYME industrial espan ola: estrategia y competencias distintivas, Civitas, Madrid.

Corson, D. et, al. 1998. Price Setting in SMEs: Some Empirical Findings. Journal of Product \& Band Management, 7 (1), 74-86, (https://doi.org/10.1108/10610429810209755), diakses 7 Maret 2018.

Covin, J.G. \& Slevin, D.P. 1989. Strategic management of small firms in hostile and benign environments. Strategic Management Journal, 10 (1), $75-87$

De Lema, D. \& Duréndez, A. 2007. Managerial behaviour of small and medium- sized family businesses: an empirical study. International Journal of Entrepreneurial Behavior \& Research, 13 (3), 151-172, (https://doi.org/10.1108/13552550710751030).

Dwyer, P., Gilkeson, J. \& List, J. 2002. Gender differences in revealed risk-taking: evidence from mutual fund investors. Economic Letters, 76 (2), $151-158$

Estes, R. \& Hosseini, J. 1988. The gender gap on wall street: an empirical analysis of confidence in investment decision making. Journal of Psychology, 122 (6), 577-590.

Fairoz, F.M., Hirobumi, T. \& Tanaka, Y. 2010. Entrepreneurial orientation and business performance of small and medium scale enterprises of Hambantota district Sri Lanka. Asian Social Science, $6(3), 34-42$. 
Forbes, D.P. \& Kirsch, D.A. 2011. The study of emerging industries: Recognizing and responding to some central problems. Journal of Business Venturing.

Geisler, E. 2018. Middle Managers as Internal Corporate Entrepreneurs: An Unfolding Agend. JSTOR. 23 (6), 52-63, (http://www.jstor.org/stable/25061821).

Gelsler, E. 1993. Middle managers as internal corporate entrepreneurs: an unfolding agenda. Interfaces, 23 (6), 52-63.

Gibb, A. 2002. In pursuit of a new 'enterprise' and 'entrepreneurship' paradigm for learning: creative destruc- tion, new values, new ways of doing things and new combinations of knowledge. International Journal of Management Reviews, 4 (3), 233-269.

Gilinsky, A., Raymond H., Santini, C. \& Eyler, R. 2010. Big bets, small wins? Entrepreneurial behavior and ROI. International Journal of Wine Business Research, $22 \quad$ (3), 238-250, (https://doi.org/10.1108/17511061011075374).

Guba, Egon, G and Yvonna S. L. 1981. Effective Evaluation, San Fransisco: Jossey- Bass Publishers.

Gupta, A., Streb, C., Gupta, V. and Markin, E., 2015. Entrepreneurial behavior during industry emergence: An unconventional study of discovery and creation in the early PC industry. New England Journal of Entrepreneurship, $18 \quad$ (2), 61-79, (https://doi.org/10/1108/NEJE-18-02-2015-B005, diakses 21 Februari 2018.

Harris, C., Jenkins, M. \& Glaser, D. 2006. Gender differences in risk assessment: why do women take fewer risks than men?. Judgment and Decision Making, 1 (1), 48-63.

Hudgens, G. \& Fatkins, L. 1985. Sex differences in risk-taking: repeated sessions on a computer simulated task. Journal of Psychology, 119 ( 3), 1970-2206.

Ireland, R., Covin, J. \& Kuratko, D. 2009. "Conceptualizing corporate entrepreneurship strategy", Entrepreneurship Theory and Practice, 33 (1), 19-46.

Johnson, J. \& Powell, P. 1994. Decision making, risk and gender: are managers different?. British Journal of Management, 5 (1),123-138.

Karp, T. 2006. The Inner Entrepreneur: Constructivistic View of Entrepreneurial Reality Construction. Journal of Change Management, 6 (3), 291-304.
Kreiser, P. \& Davis, J. 2010. Entrepreneurial orientation and firm performance: the unique impact of innovativeness, proactiveness, and risk-taking. Journal of Small Business and Entrepreneurship, 23 (1), 39-51.

Kirkley, W. 2016. Entrepreneurial Behaviour: The Role of Values. International Journal of Entrepreneurial Behavior \& Research, 22 (3), 290328. (https://doi.org/10.1108/IJEBR-02-2015-0042, diakses 7 Maret 2018.

Kuratko, D., Ireland, R., Covin, J. \& Hornsby, J. 2005. A Model of Middle- Level Managers' Entrepreneurial Behavior. ET\& P Journal,10422587.

Lau, T., Shaffer, M., Chan, K., \& Man, T. 2012. The entrepreneurial behaviour inventory: A simulated incident method to assess corporate entrepreneurship. International Journal of Entrepreneurial Behavior \& Research, 18 (6), 673-696, (https://doi.org/10.1108/13552551211268120).

Liu, G, Joyce Ko, W., Ngugi, I. \& Takeda, S. 2017. Proactive entrepreneurial behaviour, market orientation, and innovation outcomes: a study of small- and medium-sized manufacturing firms in the UK. European Journal of Marketing, (https://doi.org/10.1108/EJM-11-2016-0663)

Lofland, J. \& Lyn H. 1984. Analyzing Social Setting: A Guide to Qualitative Observation Analysis, Belmont, Cal.: Wads Worth Publising Company.

Lumpkin, G. \& Dess, G. 1996. Clarifying the entrepreneurial orientation construct and linking it to performance. Academy of Management Review, 21 (1), 135-172.

Man, T., Lau, T. \& Chan, K. 2002. The competitiveness of small and medium enterprises. A conceptualisation with focus on entrepreneurial competencies. Journal of Business Venturing, 17 (2), 123-42.

Man, T. \& Lau, T. 2005. The context of entrepreneurship in Hong Kong. Journal of Small Business and Enterprise Development, 12 (4), 46481 .

Martin, G. \& Staines, H. 1994. Management competencies in small firms. International Journal of Management Development, 13( 7), 23-34.

Mezias, S. \& Kuperman, J. 2001. The community dynamics of entrepreneurship: The birth of the American film industry, 1895-1929. Journal of Business Venturing, 16, 209-233. 
Miller, D. \& Friesen, P. 1983. Strategy-making and environment: the third link. Strategic Management Journal, 4 (3), 221-235.

Miles, M \& Huberman, A. 1984. Drawing Valid Meaning from Qualitative Data: Toward a Shared Craft. American Educational Research Association, 13 (5), 20-30

Mitchelmore, S. \& Rowley, J. 2009. Entrepreneurial competencies: a literature review and development agenda. International Journal of Entrepreneurial Behaviour \& Research, 16 (2), 92-111, (http://doi.org.10.1108/13552551011026995).

Moleong, L. 2010. Metodologi Penelitian Kualitatif. Bandung: PT. Remaja Rosdakarya.

Morris, M. \& Paul, G. 1987. The relationship between entrepreneurship and marketing in established firms. Journal of Business Venturing, 2 (3), 247-259.

Popay, J. \& Williams, G. 1998. Qualitative research and evidence-based healthcare. Journal of the Royal Society of Medicine, 35, 32-37.

Powell, M. \& Ansic, D. 1997. Gender differences in risk behavior in financial decision-making: an experimental analysis. Journal of Economic Psychology, 18 ( 6), 60-628.

Profil Portal Pemerintah Kabupaten Malang. (Online), (http://turen.malangkab.go.id/?page_id=5), diakses 8 Maret 2018.

Reijonen, H. \& Komppula, R. 2007. Perception of success and its effect on small firm performance. Journal of Small Business and Enterprise Development, $14 \quad$ (4), 689-701, (https://doi.org/10.1108/14626000710832776), diakses 15 Maret 2018.

Reynolds, P., Hay, M., Bygrave, W., \& Autio, E. 2000. Global Entrepreneurship Monitor: 2000 Exwcutive Report, Kauffman Center for Entrepreneurial Leadership at the Ewing Marion Kauffman Foundation, Kansas City, MO.

Shane, S. \& Venkataraman, S. 2000. The promise of entrepreneurship as a field of research. Academy of Management Review, 25, 217-226.

Shine, W., Haveman, H. \& Tobert, P. 2005. Risky Business? Entrepreneurship in the New IndependentPower Sector. Administrative Science Quarterl, 50, 200-232.
Smith, K. \& Gregorio, D. 2002. Bisociation, discovery and the role of entrepreneurial action. In M.A. Hitt, R.D. Ireland, S.M. Camp, \& D.L. Sexton (Eds). Strategic Entrepreneurship: Creating a New Mindset, 130-150, Oxford, UK: Blackwell Publishers.

Solhi, S. \& koshkaki, E. 2016. The antecedents of entrepreneurial innovative behavior in developing countries, a networked grounded theory approach (case study Iran). Journal of Entrepreneurship in Emerging Economies, 8 (2), (http://dx.doi.org/10.1108/JEEE-07-2015-0038)

Sorge, A., Hartmann, G., Warner, M. \& Nicholas, I. 1982. New Technology and Craftsmen's Skills in Great Britain and West Germany. Employee Relations, 4 (5), $21 \quad-\quad 23$, (http://dx.doi.org/10.1108/eb055001).

Sugiyono. 2010. Metode Penelitian Kuantitatif, Kualitatif, dan R \& D. Bandung: Alfabeta.

Thurik, R. and Wenneker, S. 2004. Entrepreneurship, small business and economic growth. Journal of Small Business and Enterprise Development, 11 (1), 140-149,

(https://doi.org/10.1108/14626000410519173).

Walter, F. \& Smallbone, D. 2011. Institutional Perspectives on Entrepreneurial Behavior in Challenging Environments. Journal of Small Business Management, 49 (1), 107-125.

Wennekers, A \& Thurik, A. 1999. Linking entrepreneurship and Economic Growth. Small Business Economic, 13, 27-55.

Wijewardena, H., Nanayakkara, G. \& Zoysa, A. 2008. The owner/manager's mentality and the financial performance of SMEs. Journal of Small Business and Enterprise Development, 15 (1), 50161.

Wiklund, J. \& Shepherd, D. 2003. Knowledge-based resources, entrepreneurial orientation, and the performance of small and medium sized businesses. Strategic Management Journal, 24 (13), 1307-1314.

Wolff, J., Pett, T. \& Ring, J. 2015. Small firm growth as a function of both learning orientation and entrepreneurial orientation: An empirical analysis. International Journal of Entrepreneurial Behavior \& Research, 21 (5), 709-730, (https://doi.org/10.1108/ IJEBR-12-2014-0221).

Zaltman, Gerald, Robert L. \& Jonny, H. 1973. Innovations and Organizations. New York: Wiley. 
Zeffane, R. 2015. Trust, personality, risk taking and entrepreneurship: Exploring gender differences among nascent and actual entrepreneurs in the United Arab Emirates. World Journal of Entrepreneurship, Management and Sustainable Development, $11 \quad$ (3), 191-209, (https://doi.org/10.1108/WJEMSD-08-2014-0025).

Zampetakis, 1. \& Moustakis, V. 2007. Entrepreneurial behaviour in the Greek public sector. International Journal of Entrepreneurial Behaviour \& Research, $13 \quad$ (1), 19-38, (http://doi.org/10.1108/13552550710725165). 